\title{
We've got the power! How customer power affects supply chain relationships
}

\author{
Barbara B. Flynn ${ }^{a, *}$, Xiande Zhao ${ }^{b}$, Baofeng Huo ${ }^{b, c}$, Jeff Hoi Yan Yeung ${ }^{b}$ \\ ${ }^{a}$ Kelley School of Business, Indiana University, 801 W. Michigan St., Indianapolis, IN 46202, USA \\ b The Chinese University of Hong Kong, Shatin, N.T., Hong Kong SAR \\ c School of Management, Xi'an Jiaotong University, Xi'an, Shaanxi, PR China
}

\section{It's all about relationships}

When it comes to supply chain management, it's all about relationships. Consider the sad story of Navistar and Ford. Navistar, a Ford supplier since 1982, provides about 225,000 diesel engines annually for Ford's F-series pickup trucks, and Ford is Navistar's biggest customer. Ford, in turn, benefits from the recent truck craze through sales of its high-profit pickups, which are powered by the Navistar engines. Sounds like a match made in heaven, right?

Not exactly. About a year ago, Ford decided to shore up its declining profitability by paying Navistar $\$ 6167$ per engine, rather than the agreedupon price of $\$ 7673$, arguing that $\$ 6167$ was a fairer price. Needless to say, Navistar didn't agree. Ford responded with the unprecedented move of debiting the invoices it received from Navistar by approximately $\$ 1500$ per engine, resulting in an annual revenue loss to Navistar of over $\$ 300$ million. Ford's apparent assumption was that Navistar would

\footnotetext{
is Adapted from Zhao, Huo, Flynn, \& Yeung (in press). The impact of power and relationship commitment on the integration between manufacturers and customers in a supply chain. Journal of Operations Management.

* Corresponding author.

E-mail address: bbflynn@iupui.edu (B.B. Flynn).
}

cave in and accede to Ford's demands because of the power that Ford wielded over Navistar.

In true David and Goliath fashion, however, Navistar fought back, ceasing production of the engines on February 26, 2007, which resulted in Ford having to curtail its truck production. Shortly thereafter, a court-ordered decree forced Navistar to resume its engine shipments and Ford to pay half of the amount that it had debited, while both parties worked out their differences. So did the little guy win, wielding power of its own?

Nothing is ever that simple. The latest twist is that Ford recently announced it is building a new factory in Chihuahua, Mexico, dedicated to 4.4-liter diesel engines, to be online by late 2009 or 2010 . Navistar is seeking more than $\$ 2$ billion in damages from Ford for failing to honor its purchase contract with Navistar, which runs through 2012, and arguing that Ford intends to produce an engine that was actually designed by Navistar.

And it goes on and on. According to the president of Planning Perspectives:

There is no trust or relationship left between Ford and Navistar. It's an extreme example of an adversarial relationship that has evolved. One has to conclude that Navistar is perceiving that Ford is taking an opportunistic view toward 
dealing with them, and that they need to do the same thing to survive (Pope, 2007).

Is this the sort of relationship you want to have in your supply chain?

In this article, we examine the topic of customer power and the effect that it has on supply chain relationships. Although the Ford and Navistar example is extreme, the concept of power is alive and well and living in supply chains everywhere. Interestingly, however, some of the effects of customer power are actually beneficial to supply chain relationships. We will examine different types of customer power and speculate about the impact that each has on the relationship between customers and suppliers. We then report the results of our research on supply chain power in Chinese supply chains, which reveals the importance of certain types of power in establishing an effective supply chain.

\section{Customer power}

When thinking about customer power, it is useful to draw upon research about the more general concept of power. French and Raven (1959) classified power into five types, and their framework has held up to extensive testing over the years. When we apply their classifications to customer power, it provides us with a useful framework.

\subsection{Expert power}

Expert power is the power that a customer has, based on knowledge, expertise, or skills that are desired by a supplier. For example, Cummins Engine is a world leader in the use of Six Sigma. Cummins routinely provides its suppliers with Six Sigma training and helps them to get started doing their own Six Sigma projects. Of course, there are benefits to Cummins as its suppliers use Six Sigma projects to improve their products and processes; however, Cummins' provision of Six Sigma training and expertise is also a powerful incentive for suppliers to seek to become Cummins suppliers. They may comply with what they believe to be Cummins' wishes as they position themselves to become Cummins suppliers, in order to take advantage of Cummins' Six Sigma expertise.

\subsection{Referent power}

Referent power exists when a supplier values identification with the customer. When you walk into the lobby of a factory, you are typically greeted by an array of plaques proudly proclaiming that the factory is a preferred supplier to Ford or other large, well-known companies. The assumption is that if a supplier is good enough to be selected as a preferred supplier for Ford, it must be pretty good. Through its potential to provide this credibility to a supplier, Ford has referent power.

\subsection{Legitimate power}

Legitimate power is natural power: the supplier believes that certain customers have a natural right to influence its actions. Because Ford was Navistar's only customer, Navistar could conceivably be willing to comply with Ford's every wish. If Navistar perceived itself to be akin to an extension of Ford, it might seem that Ford had the natural right to influence Navistar's decisions. This perception of legitimate power is typical in suppliers of large, well-known companies, such as Wal-Mart or Dell.

Notice that all three of these types of power exist in the eyes of the supplier; they are not wielded by the customer and, in fact, the customer may not even be aware that they exist. Because of this, they are known as non-mediated sources of power. Non-mediated sources of power are like a carrot, leading the supplier to be influenced without the customer taking any explicit action. The supplier, itself, decides how much or whether it will be influenced by a customer. The supplier is willingly influenced by a customer because of its perception of the customer's knowledge or expertise (expert power), reputation (referent power), or the belief that the customer has the natural right to influence it (legitimate power).

In contrast are the types of power known as mediated sources of power. These are known to the customer and are readily exercised, with the explicit intent of influencing a supplier. Mediated sources of power are more like a stick that is wielded by customers to ensure supplier compliance. The customer decides whether, when, and how to use its power to influence the supplier's behavior, by creating positive consequences, or coercing it through negative consequences.

\subsection{Reward power}

Reward power exists when the customer provides rewards that are attractive to the supplier. When the customer is pleased with a supplier, it may increase the frequency or quantity of its purchases. Back in 1982, when the relationship began, Ford rewarded Navistar by providing it with all of its Fseries engine business. If the relationship had continued on a different tack, a satisfied Ford might have rewarded Navistar with a contract for engines for additional models. 


\subsection{Coercive power}

Coercive power exists when the customer has the ability to provide punishments that are detrimental to the supplier. This was the situation with Ford and Navistar. Ford tried to use its power to coerce Navistar into lowering its engine prices. Navistar then tried to reverse the balance of coercive power by shutting down its engine assembly lines.

Customer power is particularly interesting to think about in China's rapidly emerging economy. China's national culture is high in power distance, characterized by an acceptance of power inequalities. Because non-mediated power is based on the perception of the customer's power, rather than its actual exercise, it is reasonable to expect that expert, referent, and legitimate power would be strong in China.

Guanxi, which is a behavioral outgrowth of China's cultural values, is the granting of preferential treatment to business partners in exchange for favors and obligations. Not returning a favor results in a loss of face for both the manager and his in-group. Because guanxi is based on the expectation of reciprocity, we anticipate that reward power will be especially strong in China. However, coercive power may also be potent, particularly when employed outside of the in-group.

\section{Relationship commitment}

In a supply chain, power may be an important determinant of relationship commitment, which is an attitude held by supply chain partners about the development and maintenance of a stable, longlasting, and mutually beneficial relationship. There are two types of relationship commitment. Normative relationship commitment is an ongoing relationship, over an extended period of time, which is based on mutual commitment and sharing. It's a lot like a marriage. Imagine a man and a woman who meet each other and find that they want to spend increasingly more time together. They learn to trust each other and eventually commit to each other for the long term. As they face challenges through the years, there are the inevitable disagreements; however, their commitment to each other helps them work through the issues, and it becomes even stronger over time.

In contrast, instrumental relationship commitment exists when a supplier accepts the influence of a customer only because it hopes to receive a favorable reaction. It's a lot like a relationship that is based on a woman's attraction to a man based solely on his money, fame, or good looks. While the relationship might appear rosy for a while, as soon as the woman meets someone with more money, more fame, or better looks, she won't hesitate to abandon her man in favor of another.

It's interesting to think about both types of relationship commitment in the context of a supply chain. A normative relationship takes longer to establish and demands greater investment of resources. The payoff of a long-term, committed relationship is greater for both the customer and the supplier if they are willing to put in the requisite effort. In contrast, while an instrumental relationship may be beneficial to one or both of the parties in the short term, it will fade away when the customer or supplier finds a better partner.

\section{The relationship between customer power and relationship commitment}

So, what does customer power have to do with relationship commitment? We thought that it might have a lot to do with it, so we set out to study this relationship in China. China's cultural collectivism lays the foundation for normative relationship commitment, where group interests dominate. Members of collective cultures readily subordinate their personal goals to those of the group. Normative relationship commitment may be easier to develop in China, since members of its highly collective culture experience relatedness to others as a fundamental part of themselves.

\subsection{Customer power and normative relationship commitment}

Expert power in a supply chain is a commitment to customers that possess knowledge, skills, or expertise that a supplier believes will be beneficial to it. In China's rapidly developing economy, many suppliers value their relationship with big multinational customers as a means of learning about how to compete in the global economy. We believe that this perception of expert power will cause Chinese suppliers to strive to establish normative relationships with customers.

Referent power is related to a supplier's identification with, and internalization of, the goals and values of a customer. Identification occurs when a supplier accepts a customer's influence because it admires the way the customer manages its business; internalization occurs when a supplier accepts a customer's influence because it holds values and norms of behavior that are similar. Identification and internalization may be especially potent in China, where power is transferred through interlinked guanxi networks. We believe that the perception of referent power will cause Chinese suppliers to seek to develop normative relationships with customers. 
When a supplier believes that its customer has a right to influence it and that it is obligated to accept that influence, the supplier has legitimized the customer's influence. Because of its perception of legitimate power, the supplier does not question actions taken by the customer; it simply complies. State-owned manufacturing enterprises in China were historically provided with production schedules by the central government. Despite the fact that these production schedules were frequently out of synch with market demand, they were not questioned, because the central government was believed to have the natural right to determine the policies and practices of state-owned enterprises. Thus, we believe that the perception of the legitimate power of a customer will play an important role in the desire of a supplier to develop normative relationship commitment with it.

What about mediated sources of power? They are inconsistent with normative relationship commitment because they are manipulative by nature. For example, customers' exercise of reward power manipulates the supplier through the provision of rewards for desired behaviors, and coercive power is exhibited through customers' threats to withdraw business unless the supplier engages in desired behaviors. These actions fly in the face of the trust that is at the heart of normative relationship commitment, and we believe that the use of reward and coercive power will be negatively related to normative relationship commitment.

\subsection{Customer power and instrumental relationship commitment}

By its nature, instrumental relationship commitment is based on manipulation and calculation of the benefits and costs of a relationship. Thus, we expect that expert, referent, and legitimate power will be negatively related to instrumental relationship commitment; customers which are perceived to have expert, referent, or legitimate power will be less likely to be involved in instrumental relationships. The presence of non-mediated sources of power encourages congruence in values and norms of behavior between the supplier and the customer, because the supplier willingly accepts the customer's influence. This decreases its inclination to make commitments to customers based on calculation of short-term financial benefits and costs.

In contrast, we expect that mediated sources of power will be positively related to instrumental relationship commitment, since the customer's reward or coercive power provides extrinsic motivation for commitment. This relationship may be strong in China because of the importance of guanxi, the rewards of which can include access to limited resources and controlled information; preferential terms for pricing, contracts, and credit; and protection from external competitors. Because of guanxi's obligation to exchange favors with other in-group members, Chinese suppliers place substantial weight on customers' anticipated reactions. For example, if a supplier receives a big order from a purchasing agent who is a member of his guanxi network, he is obligated to respond with a gift, favor, or concession. If this obligation is not fulfilled within a short period of time, the guanxi relationship will become strained, and the social harmony between the managers will be disturbed because the supplying manager has lost face. Thus, we expect that the use of reward power will foster stronger instrumental relationship commitment.

Similarly, a customer may use coercive power to pressure a supplier to comply with its requirements, thereby increasing the supplier's instrumental relationship commitment. If there is no guanxi between supply chain partners, there is no obligation. In fact, there is even something known as instrumental guanxi, which exists in temporary, impersonal ties that are based on transactional relationships. When the need for the relationship ceases to exist, so does the guanxi, and in a relationship without guanxi, Chinese managers will readily exploit their partners. Because the pervasiveness of guanxi makes the use of coercive power seem natural in China, we believe that a supplier's instrumental relationship commitment will be positively related to its perception of its customer's coercive power.

\section{Research study}

In order to study customer power and its effect on supply chain relationships in China, we contacted 4569 companies. Since China is very large, with uneven economic development across regions, we strategically selected five important industrial cities to analyze to provide geographic and economic diversity. Shanghai represents the Yangtze River Delta, which has China's highest GDP per capita, and Guangzhou represents the Pearl River Delta, with China's second highest GDP per capita. Both are located in southeastern China, which has the highest degree of marketization and economic reform. Tianjin represents the Bohai Sea Economic area and reflects an average level of economic reform and marketization. Chongqing, located in the southwest, represents a lower stage of economic reform and marketization. We also included Hong Kong; although most Hong Kong companies maintain manufacturing facilities in mainland China, they operate in a very 
different environment. A total of 1356 companies agreed to receive our questionnaire, and 617 usable questionnaires were returned.

We borrowed the measures of power and relationship commitment from prior research, which had developed reliable and valid measures. Some other measures had not been well documented and tested previously, so we developed new items for them based on the literature, observations during company visits, and interviews with supply chain professionals. We tested the questionnaire with supply chain professionals, in order to make sure that the questions were understandable and relevant to practices in China. After the questionnaires were returned, we performed a series of analyses to make sure that the measures we used were reliable and valid.

Although French and Raven's research on power was done in 1959 and there have been numerous studies that used their measures, there have been few research studies on power conducted in China. Because of this, we started out by looking at the power construct, so that we could see whether it fell into the same five dimensions (expert, referent, legitimate, reward, and coercive) in China as it does in Western countries. We used factor analysis to sort the items into groups that represented the same dimensions, with some interesting results. We found that power could be grouped into either four or five dimensions. When the power items were grouped into four dimensions, the reward power items were split. Half of them loaded on the same factor as the items for legitimate power, while the other half loaded on the same dimension as the items for coercive power. This was conceptually difficult to explain, so we used the five dimension result, which was also acceptable, in our analysis. We also tried to force all of the items into two dimensions, to test whether the mediated/non-mediated split would hold in China. Again, the results were difficult to interpret, with the reward power items split between the two dimensions. Thus, we did not find a good reason to collapse the five dimensions into the two dimensions often used in Western research, and found that reward power may function differently in China. We used structural equation modeling to examine the relationship between the measures, and our results are shown in Figure 1, where solid lines indicate significant positive relationships and dashed lines indicate significant negative relationships. Both expert and referent power had a positive impact on normative relationship commitment, but legitimate power did not. None of the non-mediated types of power was related to instrumental relationship commitment. In other words, although the expert and referent power of customers enhances suppliers' commitment normatively, customers do not choose to exercise it in an instrumental way. When a supplier accepts its customer's influence because of the customer's specialized knowledge and expertise or reputation, it learns from the customer. This fosters identification with and internalization of the customer's values and norms, enhancing normative relationship commitment, but does not significantly influence instrumental relationship commitment. The impact of expert power on normative relationship commitment indicates that Chinese managers have strong respect for knowledge and authority, combined with a powerful desire to learn.

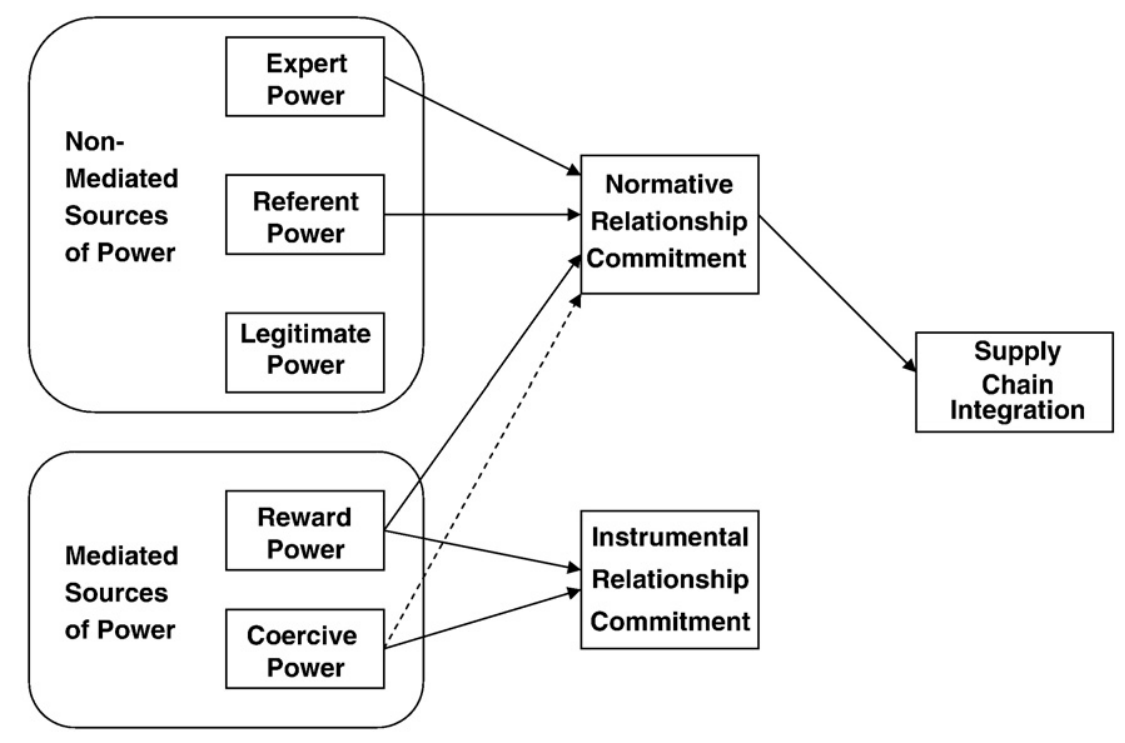

Figure 1 Relationship between power, relationship commitment, and supply chain integration 
Legitimate power was not significantly related to either type of relationship commitment. There are several reasons for this. First, the customer's natural right to influence a supplier is universally accepted in China, so this source of power is not related to any unique characteristics of the customer. Although legitimate power is strong, it is pervasive and does not particularly influence relationship commitment. Second, China's collective culture, combined with the existence of guanxi networks, causes the power base to shift from the natural rights of the customer to in-group vs. outgroup differences in the extended guanxi network. Customers aren't perceived as having power by natural right; rather, the perception of power derives from whether or not the customer is in the in-group in the supplier's extended guanxi network. Thus, the influence of a customer, merely by virtue of being a customer, is not significant.

What about mediated sources of power? Coercive power behaved according to our expectations. It was positively related to instrumental relationship commitment, but negatively related to normative relationship commitment. Thus, coercion plays a significant role in instrumental relationship commitment, but it is associated with lower levels of normative relationship commitment.

Reward power, on the other hand, had a positive impact on both normative and instrumental relationship commitment. In both China and the West, reward power brings the instrumental relationship commitment of supply chain partners. However, it also improves normative relationship commitment in China. If the customer does not reward a supplier for its good performance, the supplier's trust and normative relationship commitment will decrease. In contrast, when the customer uses reward power to meet the supplier's expectation of reciprocity, normative relationship commitment is further enhanced. Therefore, we conclude that reward power plays a very different role in Chinese culture, compared with Western cultures. This was supported by our analysis of the two dimension solution, where the loadings for reward power were split between the dimensions for mediated and non-mediated power.

We also looked at the impact of relationship commitment on supply chain integration. Supply chain integration is the extent to which an organization strategically collaborates with its supply chain partners and manages intra- and inter-organization pro- cesses to achieve effective and efficient flows of products, service, information, money, and decisions, with the objective of providing maximum value to its customers. Benefits arise from managing a supply chain as a single system, rather than individually optimizing fragmented subsystems, which involves information sharing; planning; coordination; and controlling materials, parts, and finished goods at the strategic, tactical, and operational levels. Not surprisingly, we found that normative relationship commitment had a positive impact on supply chain integration and instrumental relationship commitment was not related to supply chain integration.

Thus, suppliers should cultivate normative relationship commitment with their customers, in order to enhance supply chain integration, which previous research has shown to be vital in achieving a competitive advantage and enhancing performance. Committed customers and suppliers cooperate with each other, sharing information and integrating inter-organizational processes. When supply chain partners have an intrinsic desire to continue a relationship, supply chain integration can be achieved more readily. In contrast, instrumental relationship commitment does not have any significant influence on supply chain integration, due to its short-term and loose nature. Therefore, suppliers should refrain from cultivating instrumental relationship commitment, because it has no effect on supply chain integration and may actually damage shared values and norms in the long run.

Getting back to where we started: it's all about relationships. Imagine how the Ford and Navistar story might have turned out differently, had the parties enjoyed the sort of commitment and trust that provided a foundation for working out their differences. Instead, each of the parties is spending enormous sums of money on suits and countersuits, building new factories, and finding new business. As you establish and develop a relationship with a supply chain partner, would you rather it be more like a happy marriage or an ugly divorce?

\section{References}

French, R. P., \& Raven, B. H. (1959). The bases of social power. In D. Cartwright (Ed.), Studies in social power (pp. 155-164). Ann Arbor, MI: University of Michigan Press.

Pope, B. (2007, March 8). Ford, Navistar working toward compromise. WardsAuto.com. Retrieved from http://wardsauto.com/ ar/ford_navistar_compromise/index.html 